\title{
Tres mujeres en la vida de José Martí: Agonías de un Apóstol (Editora Política, 2012)
}

\section{Three Women in the Life of José Marti: Agonías de un Apóstol [The Agony of an Apostle] (Editora Política, 2012)}

\section{Três mulheres na vida de José Marti. Agonías de un Apóstol [A agonia de um apóstolo] (Editora Política, 2012)}

\section{Carmen María Torres-Ruisánchez}

Recibido: 14/05/2019

DOI: https: //doi.org/10.15359/tdna.35-65.23

Para quien entienda de asuntos profundos de alma atormentada, la lectura de este libro (Valdés Gallarraga, Editora Política, 2012) será un toque a la fibra más honda que nos une con un ser excepcional que una vez pisó la tierra. Y si ya dichosamente contamos en nuestra cultura contemporánea cubana con un valioso acercamiento al Martí ser humano, como es la película de Fernando Pérez: "José Martí. El ojo del canario", encontramos sin duda, en esta valiosa investigación que nos ofrece Ramiro Valdés Galarraga, una

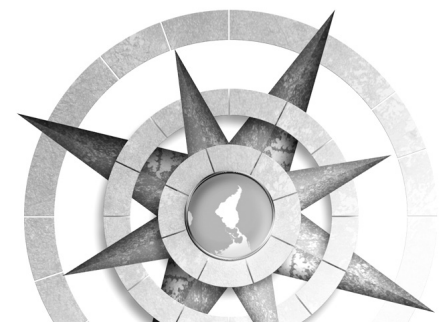

oportunidad más para asomarnos a la tremenda vida personal llena de sacrificios y agonías que vivió nuestro Apóstol, cual si fuera un largo camino de espinas.

Muy difícil nos resulta encontrar un corazón que haya ofrecido más amor y entrega a causas grandes sin esperar el mínimo de retribución, pero lamentablemente, como "Todo el que lleva luz, se queda solo" las penurias amorosas en la vida martiana también resultaron muchas veces en soledad.

Tres mujeres en la vida de Martí es ante todo un libro muy bien organizado, como el fruto de largas meditaciones y labor de búsqueda de mucho tiempo.A través de un lenguaje sencillo y bien pensado, se nos presentan los hechos a tratar de forma cronológica, aspecto muy importante para entender variados elementos en el largo itinerario de viajes que ocupó la vida de Martí; y es que Valdés Galarraga ha sembrado como 
primicia el gran respeto y comprensión al Hombre que luego se llegara a convertir en Héroe.

Por esa razón, y es sin dudas uno de los grandes valores del libro, el autor le cede constantemente la voz a los muertos, quienes nos hablan desde esos pedazos de papel que han logrado salvarse a través del tiempo: cartas de diversos remitentes nos permiten, como lectores, reconstruir la historia perdida, de la que pocas veces se habla, nos desentraña muchos de los posibles secretos personales aunque más de una vez debamos leer entre líneas lo que hay en el corazón de los que escriben. Valdés Galarraga trata de reconstruir los hechos a través de lo que los mismos protagonistas dijeron en su momento. Encontramos, junto a las reveladoras cartas de Martí a Mercado, otras a diversas personas, fragmentos de cuadernos de apuntes, anotaciones hechas hasta en el reverso de un programa de teatro, además de prácticamente todas las cartas que se conservan de Carmen Zayas-Bazán e Hidalgo, figura tan polémica para la historia.

Tras la primera advertencia del libro: "no es la historia amorosa de Martî"(Valdés Galagarra, 2012, p. 1) se precisa que solo abordará las relaciones con las tres mujeres que "influyeron ostensiblemente” en la vida del Apóstol. Sin embargo, podemos transitar por el crecimiento espiritual de un hombre que amó, y amó con locura y raciocinio, a una por encima de todas, Cuba; y siempre todo el resto de sus amores -familiares, personales, artísticos - estuvieron en constante diálogo, no siempre tranquilo, con su pasión sublime. Son justamente las incomprensiones que lo rodeaban las que lo hacen más grande, pero a la vez más atormentadora su vida.

Ramiro Valdés intenta revelarnos que María García Granados fue para el Apóstol mucho más que un idilio fugaz de juventud, y rescata una frase martiana que admite haber sacrificado ese amor por el compromiso con la que sería su esposa. Interesantes resultan las páginas dedicadas al tema, pues se compila una serie de datos sobre los que sustenta el autor la tesis que defiende, y además se enriquece el cuadro incluso con textos adyascentes como los poemas dedicados por varios poetas a María luego de su muerte. La Niña de Guatemala, para este investigador, significó una marca profunda en Martí, que vino a agravar su alma junto a las necesidades económicas y otras discrepancias que encontraba en todo lugar a causa de sus ideales.

Las diversas etapas por las que atravesó la relación del Apóstol con Carmen Zayas-Bazán están recreadas en el libro, y apreciamos cómo de la bellísima imagen de "Carmen, con aureola", "valor de Carmen" (2012, p. 47) que ilustra el deslumbramiento de recién casados 
atravesando selvas y montes, se llega al punto de "ha dejado de ser mi mujer para ser madre",(p. 99) que termina tristemente con la subida de las escaleras del Consulado de España en Nueva York, para huir en secreto con Pepito una vez más hacia Cuba.(p. 165)

El libro nos muestra que Martí amó apasionadamente a Carmen Zayas-Bazán, pero si bien esta relación tuvo numerosos altos y bajos, el padre amoroso siempre intentó conservar unida su pequeña familia, aunque no lo logró, y esta situación permanente fue una herida sangrante eterna junto a las incomprensiones de su familia materna. Podemos leer a Carmen de viva voz y es inmensamente desgarrador lo dura que es con su esposo, a pesar de haber defendido su decisión personal de unirse a él en matrimonio para toda la vida. El autor del libro lamenta el hecho de que no se conservan las cartas de Martí a su esposa, y este es en extremo conservador cuando habla del tema en medio de otras misivas a amigos como Mercado.

Ramiro Valdés no es el primero en interesarse por estas cartas de Martí a Carmen, ya un estudioso como José de la Luz León dejó entre sus trabajos inconclusos al morir uno titulado "Martí, María y las dos Carmen" en el que, al parecer de Dulce María Loynaz, intentaba reivindicar la imagen de la Zayas-Bazán en la historia. (Loynás, 2000: pp. 186-200). A petición de León, la poetisa intentó descubrir el paradero de las misivas a través de la nuera, la señora Teté Bances, viuda del hijo de Martí, pero ésta afirmó desconocerlas, pues seguramente su dueña las había destruido, y junto con las cartas, tal vez desvaneció la posibilidad de "revelar en su verdadera magnitud el tenso drama existente entre los dos".

A pesar de lo amplia que resulta la investigación de Valdés Galarraga sobre esta relación, falta quizás un complemento importante que nos muestra una cara totalmente inesperada de Carmen $\mathrm{Za}$ yas-Bazán. Luego de Martí muerto, decide enviarle a Máximo Gómez lo único que le quedaba, su hijo:
A usted que debe conocer a los hombres, no le será difícil penetrar un niño. Para Ud. soy una desco- nocida, no tengo mérito en que apoyar mi recomendación, sólo mi interés de madre que $\mathrm{Ud}$. com- prenderá fácilmente pues su espo- sa le tendrá acostumbrado a saber como queremos a nuestros hijos las madres cubanas. Acuérdese de José Martí y ame al hijo por él. Yo me quedo sola en la vida, esperan- do... (Loynaz, 2000: p.200)

Ese fue el precio más alto que pagó Carmen, y por el que más tal vez Martí trató una y otra vez de reconstruir su unión, era madre. Las cartas que nos muestra Valdés son solo la punta del "iceberg", 
pero sin duda, aguda e hiriente, de lo profundo que caló indudablemente en el alma de un ser como Martí, capaz de escribir los versos del Ismaelillo, y de haber entregado su corazón para toda la vida a quien no compartía sus ideales.

Para el colofón del libro, su autor nos reserva interesantes reflexiones suyas sobre la tan polémica paternidad de María Mantilla, acompañadas de dos cartas de ella misma defendiendo dicha paternidad. El sentido de la ética y la moral en Martí era de dimensiones muy altas que sirven a Valdés para despejar cualquier calumnia, principalmente con intenciones políticas, que siempre han pesado sobre la figura martiana. A la vez defiende la paternidad espiritual que, sin ningún lugar a dudas, poseía María, tal vez por encima del hijo de sangre, pues pudo el Apóstol cultivar más este huerto que el de su Ismaelillo.

Pero de las tres mujeres que -afirma Julio Acanda en el prólogo - han ganado el corazón de Ramiro Valdés Galarraga y se muestran en este libro, es la otra Carmen quien se lleva la preferencia, pues es justamente a su memoria a quien está dedicado todo el texto. No alcanza el autor a tener documentos suficientes para evidenciar la profunda relación que al parecer entablaron Carmen Miyares Peoli y José Martí, sin embargo hay varias referencias para saber el infinito apoyo que dio esta gran heroína de su hogar a la mayor causa del corazón del Apóstol, y así llegó a donde quizás ninguna otra mujer había llegado, compartir en cuerpo y alma su pasión por Cuba. Defiende el autor ese amor de "almas gemelas", a pesar de estar estigmatizado socialmente, y comprende, en todo el sentido de su significado, lo que representó e importó esta gran mujer para el final de la vida de nuestro Martí.

Sencillo y certero en valoraciones y criterios, puntual y consecuente con las fuentes, enamorado, respetuoso, buscador e investigador de la grandeza de alma del Héroe y del Hombre, nos afirma el autor de Tres mujeres... en sus líneas finales que su más grande aspiración es "fortalecer, más aún, la imagen de nuestro Héroe Nacional" (Valdés Galarraga, p. 166) Cree habernos develado gran información sobre dichas mujeres en Martí, y haber sido justo con la verdad, se convence de la polémica que acarreará su texto y está tranquilo con ello. Acaso Martí lo estaría, pues es muy probable que a pesar de todo cada una de estas féminas hayan ocupado lugares distintos en el gran corazón del hombre que dio mente y espíritu a su Cuba, que era la libre y no otra. Cuál de ellas se llevó la mayor parte creo que solo él lo sabe, pero nosotros, ni pudiendo escuchar toda su voz, podremos aquilatar la magnitud de su vida y sus agonías, mayores para cualquier mortal, por eso tantos ya le han tildado de extraordinario. 


\section{Referencias bibliográficas}

Dulce María Loynaz, D.M (2000). José de la Luz León”, La palabra en el aire. Ediciones Hermanos Loynaz, Pinar del Río, 2000, p. 200

Ramiro Valdés-Galarraga, R. Tres mujeres en la vida de José Martí. Editora Política, La Habana, 2012. 